\title{
Enhancement Technology for Electrospray Polyvinyl Alcohol (PVA) Nanofiber from Zuheros Nano: A Preliminary Study
}

\author{
Marhaini Mostapha ${ }^{1} *$, Win Indra Gunawan ${ }^{2}$, Sutriyono $^{3}$, Widayanti $^{2}$, Anis Yuniati $^{2 * *}$ \\ ${ }^{1}$ Bioresource and Biorefinary Laboratory, Fakulti Sains dan Teknologi, Universiti Kebangsaan Malaysia, Bangi Malaysia. \\ ${ }^{2}$ Material Physics, Pyhsics Department; ${ }^{3}$ Biology Departments, Fakulty of Science and Technology, Universitas Islam Negeri Sunan Kalijaga \\ Yogyakarta, Indonesia. \\ Email: marhainimostapha@gmail.com*, anisyuniati@yahoo.com**
}

\begin{abstract}
Polyvinyl alcohol PVA nanofiber is a biocompatible material that has numerous potential in health application include as bone and tissue implant, anti-fungal, anti-microbial, air filter and waste water treatment. In this study, the electrospin fiber has successfully fabricated byusing Zuheros Nano-electrospin machine. This is a new generation of electrospin machine which offer a faster, safer, controlled spinning conditions and highly reproducible. The 6 and $8 \mathrm{wt} \%$ of PVA was prepare and operated at different electric field of 15 and 20 $\mathrm{kV}$ at different distance between tip to collector (TDC) of 15 and $17 \mathrm{~cm}$. The physical characteristics of electrospin fiber were observed under optical microscope. Result shows that at higher voltage $20 \mathrm{kV}$, TDC $17 \mathrm{~cm}$ of $8 \mathrm{wt} \%$ PVA has produce a smooth, fine and well arrange of fibers formation compared to other electrospin parameter. The PVA electrospin membrane was successfully formed as spray durations increased to 90 minutes. The different polymer concentration (wt\%), TDC (cm) and electrospray voltage (kV) effects the PVA nano-fiber formation.
\end{abstract}

Keywords: Electrospinning, Nano-fiber, PVA, Electrospray

\section{INTRODUCTION}

Fabrication of electrospin fiber has been extensively studied due to its excellent properties include having a hollow structure, multilayer, porous, present of core and shell and its layer formation was side by side (Tarus et al. 2016). This electrospin fiber charactheristics has able it to become a good model for gas storage, sensoring, tissue remodelling, absorption and filtration which further potential applied in field of tissue engineering, wound dressing, membrane seperation, waste water filtration, bio-sensor, wearable eletronic or battery and photocatalyst (Chen et al. 2019 \& Wang et al. 2019). In addition, the poly (vinyl alcohol) (PVA)

polymer have various potential since it's a non toxic, hydrophilic and biocampatible materials with good properties include high strength, water solubility, gas permeability and thermal characteristics(Park et al. 2010). The advantages feature of both PVA and electrospin fiber, a fabrication of PVA electropin fiber via electrospin techniques were interest to explore due to the simple and effective for formation of fibers, well controlled morphology, surface, size or diameter of fibers (Tan et al. 2005 \& Lee et al. 2008).

Compared to conventional electrospray system available, there are several limitation include the uncontrolled electrospray conditions (humidity and temperature), single source of polymers, non-rotating collector, manual adjustment of target distance and voltage, less safety as setup in open environment, small scale production and passive solvent exhaust system. On the other hand, Zuheros Nano-electrospin machine has an offered upgraded features include the enviroment tightly controlled of temperature and humidity, auto-shut down voltage for safetry, adjustable voltage power supply to improve polymer deposition, secondary syringe pump with co-axial spinning head (able to spin co-polymers), secondary scanning emitter stand, multi emitter spinning head and stand (single and co-axial), taylor cone visualisation system, rotating collector (drums) (LIPI 2019). This has provided a good and improved electrospin conditions for fabrication of PVA nano fibers.

The success in fabrication of smooth, bead free and uniform electrospin fiber influence by various factors such the applied electric field, distance between the needle and collector, flow rate, and needle diameter known as electrospin parameters. For preparation of polymers solution, the solvent use for dissolution of polymer, polymer concentration (wt $\%$ ), viscosity and solution conductivity were also affects quality of electrospin formed (Haider et al. 2018). The relative humidity and temperature of electrospin were the environment factor that directly affects the succes in generation of electrospin fibers. Among all electrospin parameters, there are three main electrospin parameters were study using Zuheros Nano electrospin machine include the different polymer concentration (wt\%), TDC distance $(\mathrm{cm})$ and electrospray voltage $(\mathrm{kV})$ on the formation PVA nano-fiber as an optimisation study. This is important to ensure the reproducible and quality of electrospun fiber (smooth, beaded-free, target diameter and uniform size) that fabricate from this improved electrospin machine. 


\section{METHODOLOGY}

\section{Preparation of polymer solution}

A 8 wt $\%$ and 6 wt $\%$ of polyvinyl alcohol (PVA) solution is prepared by dissolving 0.8 and 0.6 gram of PVA into $10 \mathrm{~mL}$ of nano-pure water. The sample was stirred for 1 hour at a solution temperature $90^{\circ} \mathrm{C}$ with a stirring speed of $750 \mathrm{rpm}$.

\section{Electrospinning process}

The electrospinning process is carried out using the Zuheros-Nano electrospin machine (Lembaga Ilmu Pengetahuan Indonesia LIPI, Indonesia), by placing a 8 wt $\%$ and 6 wt $\%$ of PVA solution into the needle and sprayed at different distance from the collector (TDC) 15 $\mathrm{cm}$ and $17 \mathrm{~cm}$. Electrospinning was carried out for one hours at different operating voltage of $15 \mathrm{kV}$ and $20 \mathrm{kV}$. The electrospin machine setup as shown in Fig.1.

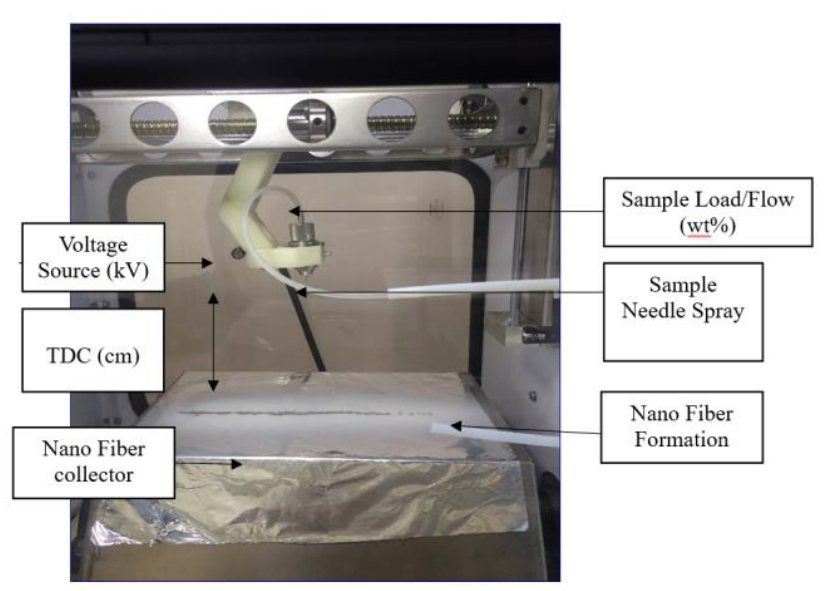

Figure 1. The Zuheros-Nano electrospray machine setup.

\section{Characterisation of electrospun fiber}

Morphological characterization and sample diameter were performed using Nikon optical microscope (YS100, Japan) equip with Nikon camera to capture electrospun fibers.

\section{RESULTS AND DISCUSSION}

\section{Effect of different electrospin voltage $(\mathrm{kV})$}

Current flow is important factor that influence the success in formation of electrospin fiber. Thus in this study two electrospin voltage of 15 and $20 \mathrm{kV}$ were used to study the effects of current flow towards the electrospin fiber formation (Fig 2 \& 3). Result from optical image shows that at higher voltage of $20 \mathrm{kV}$ (similar TDC), thinner and smoother fiber was formed, while at much lower voltage of $15 \mathrm{kV}$ thicker and uneven fiber formation. This is due to the high voltage applied on PVA polymer surface has increase the solution conductivity thus cause the polymer solution to stretch and repulse between the polymer jet create unstable state of polymer (Acik et al. 2019 \& Tarus et al. 2016). At critical voltage, these unstable polymers will spin from spherical droplet to deform Taylor cone and finally form ultrafine nanofibers (Laudenslager \& Sigmund 2012).
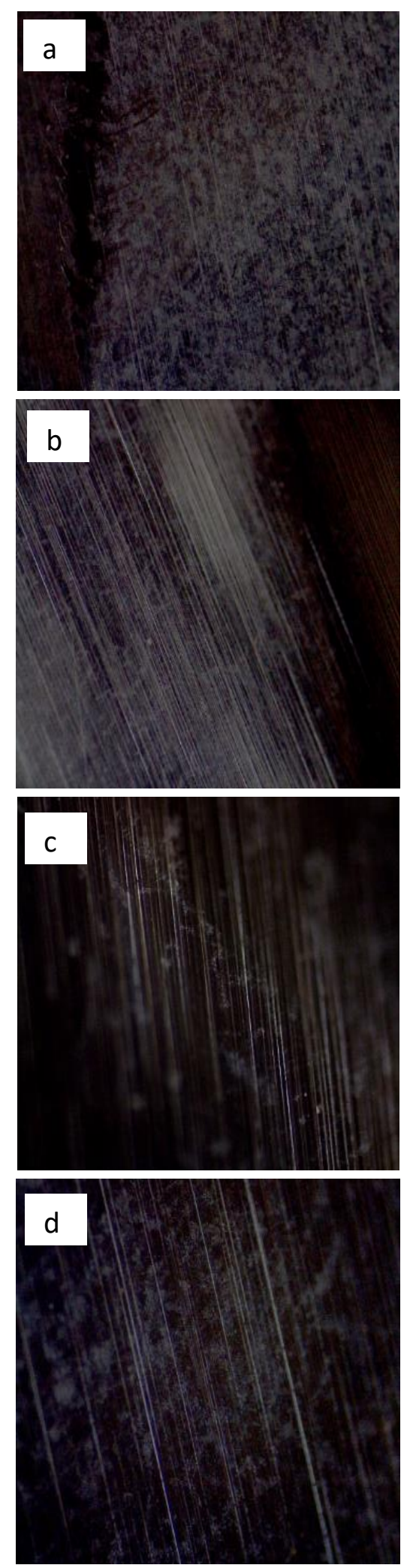

Figure 2. The optical image of $6 \mathrm{wt} \%$ PVA electrospin fiber a) voltage $15 \mathrm{kV}$, TDC $15 \mathrm{~cm} \mathrm{~b})$ voltage $20 \mathrm{kV}$, TDC $15 \mathrm{~cm} \mathrm{c}$ ) voltage $15 \mathrm{kV}$, TDC $17 \mathrm{~cm} \mathrm{~d}$ ) voltage $20 \mathrm{kV}$, TDC $17 \mathrm{~cm}$. 
Similar results were also by Sill \& Recum (2008) reported small-diameter nanofibers formation at higher voltage electrospin. However the critical applied voltage may vary from polymer to polymer and beaded nano fibers will form as result of too high voltage during electrospin (Haider et al. 2018). As qualitatively observed, at lower voltage electrospray of $15 \mathrm{kV}$ more time needed for the polymer solution spray thus require more PVA volume of solution to form fiber as compared to $20 \mathrm{kV}$. Thus we suggest that $20 \mathrm{kV}$ was a good electric voltage value for formation of PVA electrospin fiber via Zuheros-Nano.
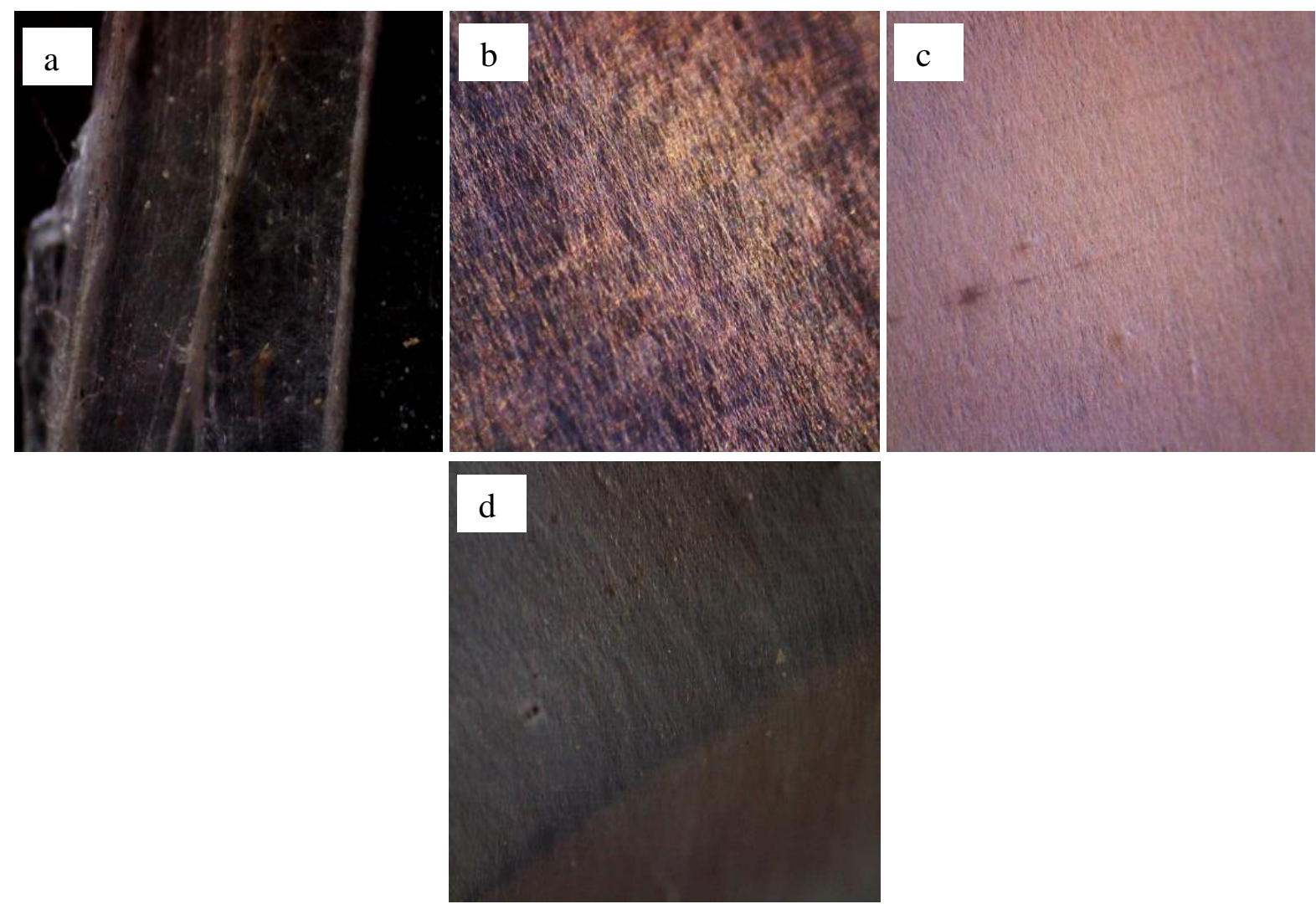

Figure 3. The optical image of 8 wt $\%$ PVA electrospin fiber a) voltage $15 \mathrm{kV}$, TDC $15 \mathrm{~cm} \mathrm{~b}$ ) voltage $20 \mathrm{kV}$, TDC $15 \mathrm{~cm}$ c) voltage $15 \mathrm{kV}$, TDC $17 \mathrm{~cm}$ d) voltage $20 \mathrm{kV}$, TDC $17 \mathrm{~cm}$.

\section{Effect of different electrospin distance tip to collector (cm)}

Figure $2 \& 3$ shows the optical image of electrospun fiber at different tip to collector (TDC) at $15 \mathrm{~cm}$ and $17 \mathrm{~cm}$. With other electrospray parameter constant, the increase of TDC shows smoother, uniform and thicker electrospin fiber formation. This happen due to higher TDC $(\mathrm{cm})$, more time for polymer to travel from needle tip to aluminium collector, more time for solvent to evaporates, thus solidification rate higher due to rapid transition of liquid to solid as in Fig 4 (Homayoni et al. 2009). In addition as more travel distance during electrospray cause higher electric field strength on polymer solution from voltage exposure, higher stretch of polymer results in thin uniform fibers due to the predominance of non-axis symmetric fiber (Meli et al. 2010). This can clearly seen on results of $17 \mathrm{~cm}$ TDC. However, if shorter TDC tends to form much rough fiber formation due to solvent not fully evaporates, short time for solidification of polymers which higher chances form ununiform fine structure or beaded fiber as can be observed in Figure $2 b$ for $15 \mathrm{~cm}$ TDC. Similar results was reported in Meli et al. 2010 which explained that droplet of polymers solution and beaded fiber formation was promoted when electrospray conditions at high charge densities over axis-symmetric instability modes. This result suggest that TDC of $17 \mathrm{~cm}$ was able to form smooth thin fiber compared to TDC $15 \mathrm{~cm}$ tends to form ununiform or beaded fibers.

\section{Effect of PVA polymer concentration}

The polymer concentration has been one of important factors that influence the fabrication of electrospun fiber. In this study the 6 wt $\%$ and 8 wt $\%$ of PVA polymer concentration were studied. From qualitative observation, the 6 wt \% PVA showed much lower viscousity compared to $8 \mathrm{wt} \%$. Since the $6 \mathrm{wt} \%$ PVA polymer solution was less viscous, thus it tends to form 
droplet which require more time and polymer solution (volume) before the fibers started to spray. While for the 8 wt \% PVA polymer solution was more viscous, thus less droplet formation and the polymer will straight away spin to form fibers. Kong and Ziegler (2013) were also reported less bead or beadless nanofiber succesfully formed using higher concentrations of polymers. As compared with both polymer concentrations, higher PVA of $8 \mathrm{wt} \%$ was better peformance in fabrication of electrospin fiber since less polymer solution (volume) needed and faster fiber formation. Result was in compliment with other studies which explained that lower polymer concentration indicates that not enough polymers to entangle and spin through to form fiber (Murthe et al. 2019 \& Acik et al. 2019).

The optical microscope image in Fig 2 showed that at $6 \mathrm{wt} \%$ less fiber formation and much thinner, compared to 8 wt \% (Fig 3) fiber was packed, thicker and smoother. This is due to more viscous polymer solution, higher polymers entanglement occurs and better chances to form uniform fiber (Murthe et al. 2019 \& Acik et al. 2019). Study by Huang et al. (2003) \& Kong and Ziegler (2013), reported that electrospray using $6 \mathrm{wt} \%$ of polymer solutions have higher possibility to form beaded fiber, while 7 to $10 \mathrm{wt} \%$ polymer solution tend to form beaded free fiber. However if too high polymer concentration, the viscouscity of polymers make it unable to flow through syringe needle and may require more spray durations, higher voltage and flow rate to fabricate its fiber. This was non ecomonical especially to upscale for industrial industry.

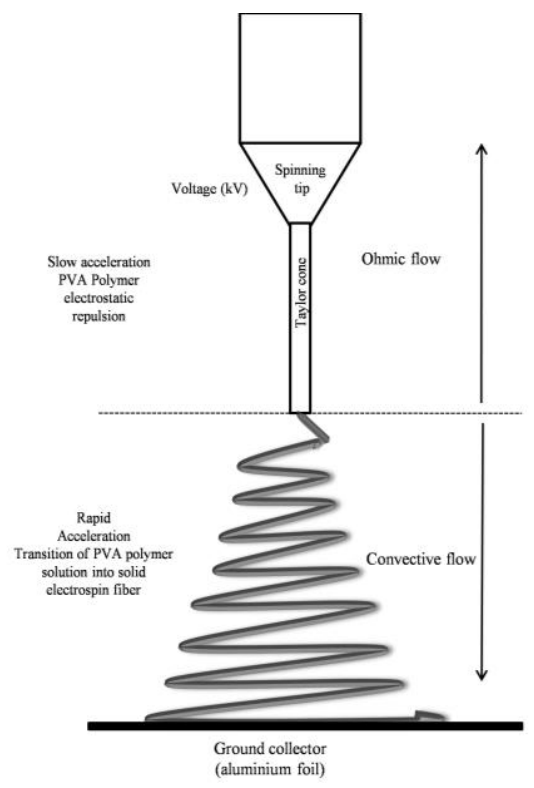

Figure 4. The principle of fabrication PVA electrospin fiber.

Beside the electrospinning and solution parameters, recently it has been reported that environmental (ambient) factors such as relative humidity and temperature also affect the diameter and morphology of the nanofibers (Huan et al. 2015; Pelipenko et al. 2013).
Humidity cause changes in the nanofibers diameter by controlling the solidification process of the charged jet. However in this study using Zuheros nano electrospin machine, the relative electrospray humidity $(71.50 \pm 2.64 \%)$ and temperature $\left(28.9 \pm 0.5^{\circ} \mathrm{C}\right)$ were well controlled. Thus it can assume that the solidifaction of polymers was homogen.

\section{Formation of PVA electrospin membrane}

The PVA electrospin membrane was successfully formed as spray durations increased to 90 minutes (Fig 5 ). The membrane can easily detach from aluminium foil after electrospray. Compared to other conventional electrospin machine, to form a membrane the spray duration need up to 12-14 hours to obtain sufficiently thick around $10 \mu \mathrm{m}$ (Wu et al. 2005). This shows that Zuheros Nano electrospin machine has better peformance in formation of electrospin membrane. However the succes in fabrication of nano fiber membrane may differ depends on type of polymer.

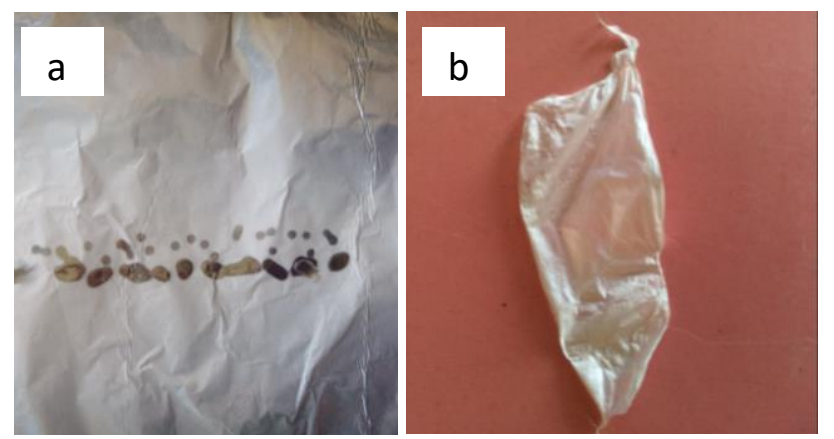

Figure 5. The PVA (a) electrospin fiber on alluminium and (b) fiber membrane.

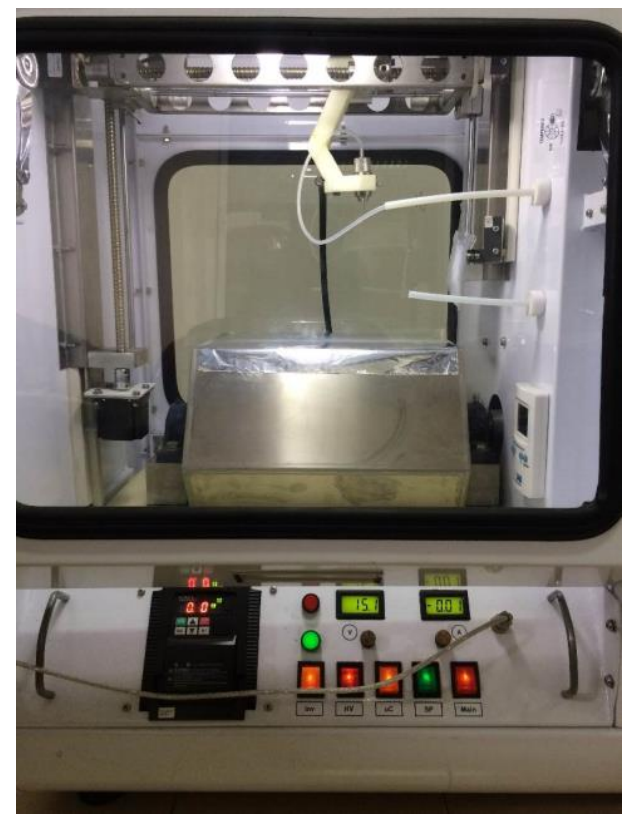

Figure 6. The Zuheros nano electrospin fiber machine 


\section{CONCLUSION}

The different polymer concentration (wt \%), TDC $(\mathrm{cm})$ and electrospray voltage $(\mathrm{kV})$ effects the PVA nanofiber formation. Out of all parameters, the optimised combination conditions was using $8 \mathrm{wt} \%$ PVA polymer concentration, voltage $20 \mathrm{kV}$ and spray distance of $17 \mathrm{~cm}$. The Zuheros nano electrospray machine has huge potential in nano-material application which improves the electrospray peformance in formation of electrospun fiber and membrane.

\section{REFERENCES}

Acik, G. \& Altinkok, C. 2019. Polypropylene microfibers via solution electrospinning under ambient conditions. Journal of Applied Polymer Science 48199:1-6.

Chen, L., Wang, S., Yu, Q., Topham, P.D., Chen, C. \& Wang, L. 2019. A comprehensive review of electrospinning block copolymers. Soft Matter 15(12): 2490-2510.

Haider, A., Haider, S. and Kang, I.K., 2018. A comprehensive review summarizing the effect of electrospinning parameters and potential applications of nanofibers in biomedical and biotechnology. Arabian Journal of Chemistry 11(8): 11651188.

Huan, S., Liu, G., Han, G., Cheng, W., Fu, Z., Wu, Q. \& Wang, Q. 2015. Effect of experimental parameters on morphological, mechanical and hydrophobic properties of electrospun polystyrene fibers. Materials 8(5): 2718.

Huang, Z.M., Zhang, Y.Z., Kotaki, M. \& Ramakrishna, S. 2003. A review on polymer nanofibers by electrospinning and their applications in nanocomposites. Composite Science Technology 63:2223-2253.

Homayoni, H., Ravandi, S.A.H. \& Valizadeh, M. 2009. Electrospinning of chitosan nanofibers: Processing optimization. Carbohydrate Polymers 77(3): 656-661.

Kong, L. \& Ziegler, G.R. 2013. Quantitative relationship between electrospinning parameters and starch fiber diameter. Carbohydrate Polymer 92:1416-1422.

Laudenslager, M.J. \& Sigmund, W.M. 2012. "Electrospinning” Encyclopedia of Nanotechnology. Springer Publishers, 769775.
Lee, K. H., Ohsawa, O., Lee, S., Park, J. C., Kim, K. W., Kim, H. Y., Watanabe, Y. \& Kim, I. S. 2008. A study on the $\mathrm{PVAc} / \mathrm{FeSO}_{4}$ composite nanofiber via electrospinning. Sen'i Gakkaishi 64, 306-311.

Lembaga Ilmu Pengetahuan Indonesia LIPI (2019), LIPI Pusat Sasana Widya Sarwono (SWS) Jl. Jend. Gatot Subroto 10, Jakarta 12710, Indonesia.

Meli, L., Miao, J., Dordick, J.S. \& Linhardt, R.J. 2010. Electrospinning from room temperature ionic liquids for biopolymer fiber formation. Green Chemistry 12(11): 18831892.

Murthe, S.S., Saheed, M.S.M., Perumal, V., Saheed, M.S.M. \& Mohamed, N.M. 2019. Electrospun Nanofibers for Biosensing Applications. In Nanobiosensors for Biomolecular Targeting. 253-267.

Park, J.C., Ito, T., Kim, K.O., Kim, K.W., Kim, B.S., Khil, M.S., Kim, H.Y. \& Kim, I.S. 2010. Electrospun poly (vinyl alcohol) nanofibers: effects of degree of hydrolysis and enhanced water stability. Polymer Journal 42(3): 273.

Pelipenko, J., Kristl, J., Jankovic', B., Baumgartner, S. \& Kocbek, P. 2013. The impact of relative humidity during electrospinning on the morphology and mechanical properties of nanofibers. International Journal Pharmacy 456 (1):125134.

Purnawati, D., Nugraheni, A.D., Shalihah, H. \& Laraswati, L. Pembuatan Nanofiber PolivinilAlkohol (PVA) Dengan Metode Electrospinning Sebagai Masker Debu Vulkanik. Jurnal Fisika Indonesia 21(1): 24-26.

Sill, T.J. \& von Recum, H.A. 2008. Electrospinning: applications in drug delivery and tissue engineering. Biomaterials 29 (13):1989-2006.

Tan, S. H., Inai, R., Kotaki, M. \& Ramakrishna, S. 2005. Systematic parameter study for ultra-fine fiber fabrication via electrospinning process. Polymer 46, 6128-6134.

Tarus, B., Fadel, N., Al-Oufy, A. \& El-Messiry, M. 2016. Effect of polymer concentration on the morphology and mechanical characteristics of electrospun cellulose acetate and poly (vinyl chloride) nanofiber mats. Alexandria Engineering Journal 55(3): 2975-2984.

Wang, C., Wang, J., Zeng, L., Qiao, Z., Liu, X., Liu, H., Zhang, J. \& Ding, J. 2019. Fabrication of electrospun polymer nanofibers with diverse morphologies. Molecules 24(5):834.

Wu, L., Yuan, X. \& Sheng, J. 2005. Immobilization of cellulase in nanofibrous PVA membranes by electrospinning. Journal of Membrane Science, 250(1-2):167-173. 
THIS PAGE INTENTIONALLY LEFT BLANK 